\title{
BLASTOCYSTS PRODUCTION AND COLLECTION IN ALBINO SYRIAN HAMSTER USING SUPEROVULATION AND INTRAUTE- RINE ARTIFICIAL INSEMINATION IN NON-BREEDING SEASON
}

\author{
A. AMIRI DIVANI ${ }^{1}$, D. MEHRABANI ${ }^{1}$, A. TAMADON ${ }^{1}$, \\ O. KOOHI-HOSSEINABADI ${ }^{2} \&$ S. ZARE ${ }^{1}$ \\ ${ }^{1}$ Transgenic Technology Research Center, Shiraz University of Medical Sciences, \\ Shiraz, Iran; ${ }^{2}$ Center of Comparative and Experimental Medicine, \\ Shiraz University of Medical Sciences, Shiraz, Iran

\section{Summary} \\ Amiri Divani, A., D. Mehrabani, A. Tamadon, O. Koohi-Hosseinabadi \& S. Zare, 2017. \\ Blastocysts production and collection in albino Syrian hamster using superovulation and \\ intrauterine artificial insemination in non-breeding season. Bulg. J. Vet. Med., 20, No 2, \\ $169-173$.

\begin{abstract}
In vivo blastocyst production and collection using superovulation and intrauterine insemination was established in albino Syrian hamsters. Twenty female albino hamsters were injected pregnant mare serum gonadotropin (PMSG, $25 \mathrm{IU}$ ) in non-breeding season and $48 \mathrm{~h}$ or $56 \mathrm{~h}$ later, $25 \mathrm{IU}$ of human chorionic gonadotropin (hCG) were injected. Both groups were divided into two subgroups of natural mating and artificial insemination. The former group was mated with a fertile male ( 1 male for 2 females) after hCG injection and in the next morning, the hamsters with vaginal plug were regarded as pregnant. In the artificial insemination group, intrauterine artificial insemination of $1 \times 10^{8}$ sperms was done $12 \mathrm{~h}$ after hCG injection. Blastocysts were counted at 3.5 days after mating or insemination. However, $48 \mathrm{~h}$ and $56 \mathrm{~h} \mathrm{hCG}$ and natural mating and $48 \mathrm{~h} \mathrm{hCG}$ and artificial insemination were without blastocyst; however the method of $56 \mathrm{~h} \mathrm{hCG}$ and artificial insemination produced of $15 \pm 5$ (mean and standard deviation) blastocysts in each albino hamster in the winter.
\end{abstract}

Key words: artificial insemination, blastocyst, hamster, non-breeding season, superovulation

Some hamster strains including golden hamster, Brandt's hamster, and Romanian hamster are endangered (IUCN, 2012). To preserve vulnerable animals, assisted reproductive technologies can be used including collection and preservation of genome or cells such as fibroblast, semen, and embryos at different stages of deve- lopment especially blastocysts (Mehrabani et al., 2014).

Blastocysts can be produced by natural mating or artificial insemination. Hamsters have a seasonal pattern of reproduction and cold weather stops routine estrous cycles in female golden hamsters (Simonneaux et al., 2012). Therefore, pro- 
duction of blastocysts by superovulation and artificial insemination can be proposed. To increase more blastocysts in the hamster, pregnant mare's serum gonadotropin (PMSG) for ovarian stimulation and superovulation following human chorionic gonadotropin (hCG) for ovulation induction is applied (Sarsaifi et al., 2013). In hamsters, embryo production also has been induced using PMSG alone (Doetschman et al., 1988).

Apart from the type and number of hormones for superovulation, timing and type of insemination can affect the result of superovulation. Embryos have been produced with various injection interval timing of hormones (PMSG and hCG) in different rodents, such as $50 \mathrm{~h}$ interval in rats (Cornejo-Cortes et al., 2006), $48 \mathrm{~h}$ interval in mice (Ertzeid \& Storeng, 1992) and $56 \mathrm{~h}$ interval in hamsters (Lee et al., 2005).

In many studies, embryos are obtained by natural mating in hamsters (Lee et al., 2005) nonetheless in another research embryos are produced by artificial insemination (Smith et al., 1987). The aim of the present study was establishment of in vivo blastocysts production and collection using superovulation and intrauterine insemination in albino Syrian hamsters during non-breeding season.
All procedures and treatments were performed according to the Animal Care Ethical Rules of Shiraz University of Medical Sciences, Shiraz, Iran. Twenty adult female albino hamsters $(100 \pm 10 \mathrm{~g})$ were selected in the diestrous phase using vaginal smears evaluation. PMSG (25 IU, Pregnecol, Bioniche Animal Health, Armidale, Australia) was intraperitoneally injected. The hamsters were divided into two groups which were intraperitoneally injected hCG (25 IU, LG Life Sciences, Jeonbuk-do, Korea) after $48 \mathrm{~h}$ (the first group) and $56 \mathrm{~h}$ (the second group). Each group was divided into two natural mating and artificial insemination subgroups $(n=5)($ Table 1).

Hamsters of the natural mating groups were mated with fertile males after hCG injection ( 1 male for 2 females) and in the next morning observation of the vaginal plug was regarded as pregnancy. In the artificial insemination groups, $12 \mathrm{~h}$ after $\mathrm{hCG}$ injection, intrauterine artificial insemination was done in both horns. In detail, for sperm collection, a young adult male albino hamster was euthanised by ketamine $(50 \mathrm{mg} / \mathrm{kg}$, Woerden, Holland), xylazine (5 mg/kg, Woerden, Holland) and cervical dislocation. Tails of epididymis of the hamster were isolated under sterile conditions and were chopped with

Table 1. Experimental design for evaluation of the effect of superovulation and intrauterine artificial insemination for blastocysts production and collection in albino Syrian hamsters in non-breeding season

\begin{tabular}{lccccc}
\hline \multirow{2}{*}{ Groups } & \multicolumn{5}{c}{ Time (h) } \\
\cline { 2 - 6 } & 0 & 48 & 56 & 60 & 68 \\
\hline G1 $(\mathrm{n}=5)$ & PMSG & hCG + NM & & & \\
G2 $(\mathrm{n}=5)$ & PMSG & & hCG + NM & & \\
G3 $(\mathrm{n}=5)$ & PMSG & hCG & & AI & \\
G4 $(\mathrm{n}=5)$ & PMSG & & hCG & & AI \\
\hline
\end{tabular}

Abbreviations: PMSG, pregnant mare serum gonadotropin; hCG, human chorionic gonadotropin; $\mathrm{NM}$, natural mating; AI, artificial insemination 
a scalpel and were transferred into a 1.5 $\mathrm{mL}$ microtube containing $1 \mathrm{~mL}$ phosphate buffered saline solution (PBS, $37.5^{\circ} \mathrm{C}$ ) and were incubated in a dry incubator (Iran Khodsaz Co., Tehran, Iran) for 20 min. Then, sperm motility was examined on a $37.5{ }^{\circ} \mathrm{C}$ warm slide under a microscope. Sperm concentration was determined using hemocytometer counting. After determination of appropriate concentration, $1 \times 10^{8} \mathrm{sperm} / \mathrm{mL}$ was injected into each uterine horn using a $37.5{ }^{\circ} \mathrm{C}$ warm insulin syringe (Fig. 1A). For this purpose, female hamsters were anesthetised by ketamine and xylazine. Abdominal hairs were shaved and then were disinfected with povidone-iodine solution and draping was done. An incision about $1 \mathrm{~cm}$ was done in midline region of abdomen. Uterine horns were exposed using a forceps. Intrauterine injection of $0.2 \mathrm{~mL}$ sperm solution was performed using a 26 gauge needle inserted into an insulin syringe in a 30 degrees angle with uterine lumen in the cranial third of each horn (Fig. 1B). The uterine horns were returned to their place. Muscles and skin were sutured with 4-0 vicryl suture and 3-0 nylon suture, respectively. Finally, tetracycline antibiotic was sprayed on the skin and postoperative recovery was monitored.

After 3.5 days post-coitus or postartificial insemination, uterine horns were flushed by PBS to collect blastocysts. In detail, each female hamster was euthanised by ketamine $(50 \mathrm{mg} / \mathrm{kg})$, xylazine ( 5 $\mathrm{mg} / \mathrm{kg}$ ) and cervical dislocation. Under class I laminar flow (Jal Tajhiz Labtech Co., Karaj, Iran), alcohol was sprayed on abdomen and hamsters were dissected. The uterus was cut from ovaries and vagina and was transferred to a plate containing PBS under sterile conditions. The uterine horns were filled with $37^{\circ} \mathrm{C}$ PBS flushing medium (Fig. 2A) and then the cranial tips were cut using a scissors. Blastocysts were collected and counted (Fig. 2B) under a loop microscope (Optika, Italy).

Albino hamsters submitted to $48 \mathrm{~h}$ and $56 \mathrm{~h}$ hCG with natural mating and $48 \mathrm{~h}$ hCG with artificial insemination protocols were without blastocyst. The method including $56 \mathrm{~h} \mathrm{hCG}$ and artificial insemination produced $15 \pm 5$ (mean $\pm \mathrm{SD})$ blastocysts in each albino hamster in winter.

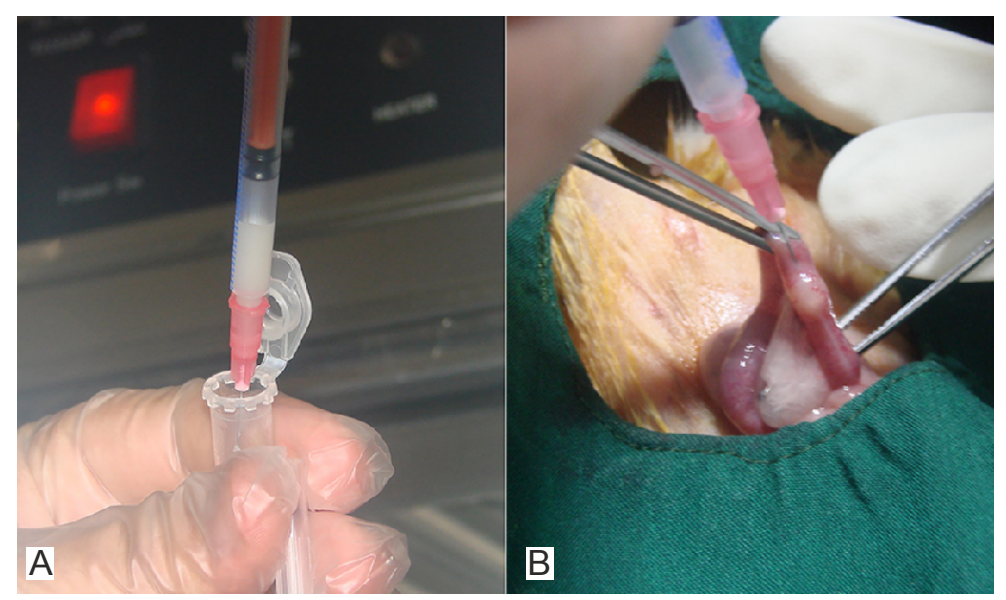

Fig. 1. A. Collection of counted albino hamster sperms from $37.5^{\circ} \mathrm{C}$ incubated tail of epididymis in phosphate buffer saline; B. Intrauterine artificial insemination of female hamster. 


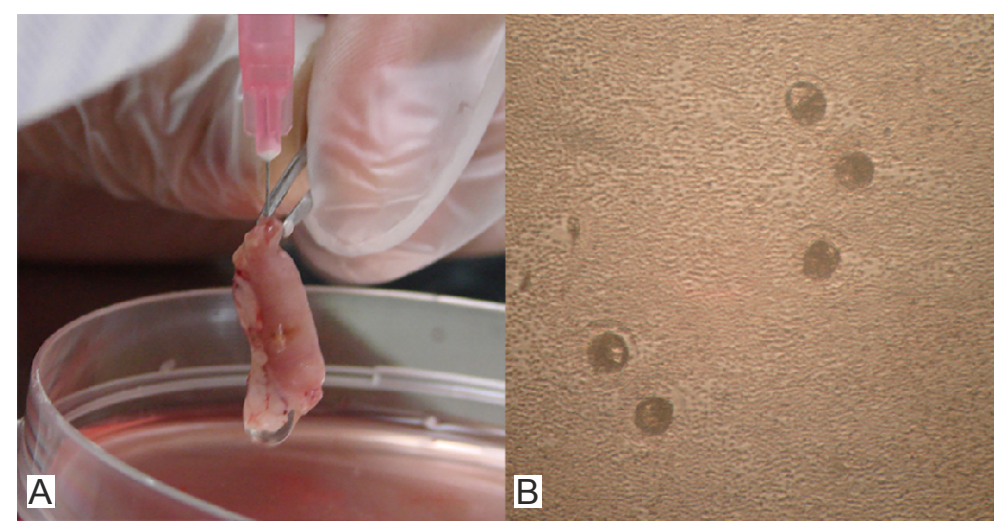

Fig. 2. A. Hamster uterine flushing by phosphate buffer saline; B. Collected hamster blastocysts.

Hamsters' superovulation with PMSG following hCG has been done in various studies. In a study, 409 blastocysts were produced in 31 hamsters (about 13 blastocysts per hamster) using PMSG without hCG (Doetschman et al., 1988). Consistent with our findings, 28 to 29 blastocysts yield per hamster with the same proportion of both hormones as used in the present study were obtained in breeding season (Lee et al., 2005). Superovulated hamsters (PMSG and hCG with a $56 \mathrm{~h}$ interval) had a rise in blastocysts number from 15 (control group) to 28-29 (Lee et al., 2005). Likewise, mouse superovulation (PMSG and hCG with a $48 \mathrm{~h}$ interval) increased blastocyst numbers from 33 (control group) to 52 (Ertzeid \& Storeng, 1992). In addition, in Wistar rats, most embryo numbers were obtained by PMSG and hCG with $50 \mathrm{~h}$ interval (CornejoCortes et al., 2006). Therefore, the application of PMSG and hCG at $56 \mathrm{~h}$ interval can induce superovulation in nonbreeding season in albino hamster.

Intrauterine injection of $0.2 \mathrm{~mL}$ suspension containing $1 \times 10^{8}$ sperms in nonbreeding season in superovulated albino hamsters produced blastocysts. The method by which artificial insemination is done varies as the sperm volume. Consistent with our findings, hamsters have been inseminated by the same operation with $1.7 \times 10^{8} \mathrm{sperms} / \mathrm{mL}$ in a 0.2 volume into each uterine horn (Smith et al., 1987). Rats were injected through surgical exposure into each uterus by $10 \times 10^{6}$ to $20 \times 10^{6}$ spermatozoa in a $0.1 \mathrm{~mL}$ sperm suspension volume (Orihuela et al., 1999). Therefore, intrauterine artificial insemination can be suggested for blastocyst production in hamster during non-breeding season.

In hamsters, breeding ceases during the winter months and gonadal regression occurs (Heldmaier \& Steinlechner, 1981). In the laboratory, when hamsters were exposed to short winter-like non-breeding photoperiods, gonadal regression occurs and in both males and females, levels of offensive aggression were elevated (Jasnow et al., 2000). Therefore, during nonbreeding season inactivation of male and female gonads reduced the chance of success in reproduction even after superovulation and natural mating.

In conclusion, equal doses of PMSG and hCG (25 IU) applied at $56 \mathrm{~h}$ interval and intrauterine artificial insemination produced $15 \pm 5$ blastocysts in each albino Syrian hamster during the non-breeding 
season. Nevertheless, natural mating after PMSG and hCG ( $48 \mathrm{~h}$ or $56 \mathrm{~h}$ interval) and artificial insemination after PMSG and $\mathrm{hCG}$ (48 $\mathrm{h}$ interval) were without blastocyst during the non-breeding season. This study presented a suitable timing, rapid and practical method to produce and collect blastocysts using superovulation and intrauterine insemination in albino Syrian hamster in non-breeding season.

\section{REFERENCES}

Cornejo-Cortes, M. A., C. Sánchez-Torres, J. C. Vázquez-Chagoyán, H. M. Suárez-Gómez, G. Garrido-Fariña \& M. A. MerazRíos, 2006. Rat embryo quality and production efficiency are dependent on gonadotrophin dose in superovulatory treatments. Laboratory Animal, 40, 87-95.

Doetschman, T., P. Williams \& N. Maeda, 1988. Establishment of hamster blastocystderived embryonic stem (ES) cells. Developmental Biology, 127, 224-227.

Ertzeid, G. \& R. Storeng, 1992. Adverse effects of gonadotrophin treatment on preand postimplantation development in mice. Journal of Reproduction and Fertility, 96, 649-655.

Heldmaier, G., \& S. Steinlechner, 1981. Seasonal control of energy requirements for thermoregulation in the djungarian hamster (Phodopus sungorus), living in natural photoperiod. Journal of Comparative Physiology B: Biochemical, Systemic, and Environmental Physiology, 142, 429-437.

IUCN, 2012. IUCN Red List of Threatened Species. www.iucnredlist.org (4 June 2015 date last accessed).

Jasnow, A. M., K. L. Huhman, T. J. Bartness, G. E. Demas, 2000. Short-day increases in aggression are inversely related to circulating testosterone concentrations in male Siberian hamsters (Phodopus sungorus). Hormones and Behavior, 38, 102-110.

Lee, S. T., T. M. Kim, M. Y. Cho, S. Y. Moon, J. Y. Han \& J. M. Lim, 2005. Deve- lopment of a hamster superovulation program and adverse effects of gonadotropins on microfilament formation during oocyte development. Fertility and Sterility, 83, 1264-1274.

Mehrabani, D., R. Mahboobi, M. Dianatpour, S. Zare, A. Tamadon, \& S. E. Hosseini, 2014. Establishment, culture, and characterization of guinea pig fetal fibroblast cell. Veterinary Medicine International, 2014, Article ID 510328.

Orihuela, P. A., M. E. Ortiz \& H. B. Croxatto, 1999. Sperm migration into and through the oviduct following artificial insemination at different stages of the estrous cycle in the rat. Biology of Reproduction, 60 , 908-913.

Sarsaifi, K., M. A. Omar, R. Yusoff, A. W. Haron, H. Hani, N. Yimer, J. Vejayan, W. N. Soe \& A. M. Othman, 2013. Development of superovulation program and heterologous in vitro fertilization test assessment in hamsters. Asian Journal of Animal and Veterinary Advances, 8, 796-805.

Simonneaux, V., I. Bur, C. Ancel, L. Ansel \& P. Klosen, 2012. A kiss for daily and seasonal reproduction. Progress in Brain Research, 199, 423-437.

Smith, T. T., F. Koyanagi \& R. Yanagimachi, 1987. Distribution and number of spermatozoa in the oviduct of the golden hamster after natural mating and artificial insemination. Biology of Reproduction, 37, 225-234.

Paper received 09.03.2015; accepted for publication 08.05.2015

\section{Correspondence:}

Amin Tamadon

Transgenic Technology Research Center, Shiraz University of Medical Sciences,

Shiraz, Iran

tel/fax: +98 7132341025 ,

e-mail: amintamaddon@yahoo.com 